Welcome emphasis is laid on research and development in the White Paper, which in referring to a start on longer-range planning for defence research and development with the constitution of the Defence Research Policy Committee, lays stress on the importance of encouraging scientific research and development at a time when economic considerations must severely limit expenditure on new equipment. Although there is evidence that, with the appointment of Sir Henry Tizard as chairman of the Advisory Council on Scientific Policy, knowledge of developments over the whole field of science will be pooled, to the benefit both of the civilian community and of national defence, there is not the same evidence of close co-operation elsewhere.

The references to the Defence Research Policy Committee are, however, encouraging. Through its close link with the Chiefs of Staff, the Committee will be continuously aware of the latest concepts of strategy and operational thought and will itself be able to influence those concepts by reason of its knowledge of future trends in the field of defence science. The Committee will also study programmes for research and development formulated by the Service and Supply Departments in connexion with the preparation of annual estimates, and it will also have brought before it all problems which arise on the higher organisation of defence research and development, and on the requirements of the Service and Supply Departments for scientific man-power, and also major projects for new establishments.

Such organisation providing for effective coordination of effort is the right instrument and condition for securing whole-hearted co-operation. It is essential that a like effort should be made in other fields. Co-operation, as Sir George Schuster has pointed out, is a two-way effort, demanding a lead from the Government as well as response from industry and from the nation. It requires organisation and much more than passive acquiescence in regulations or sporadic demands of the Government from individual interests. Whether or not industrial and trade associations become, as Sir George Schuster suggests, bodies to whom a general strategic task can be entrusted with confidence, to be worked out in close collaboration with the trade unions, no such instrument can be substituted for resolute leadership by the Government.

\section{DEFECTIVE COLOUR VISION IN INDUSTRY}

A COMMITTEE of the Colour Group of the Physical Society has performed a valuable task for the benefit of the community in preparing its recent "Report on Defective Colour Vision in Industry"*. It is written in a style which will be readily understandable by non-technical readers. Starting with a clear account of the nature and incidence of defective colour vision, it goes on to describe various colour vision tests, and mentions an almost alarming variety; an interesting chapter deals with colour vision in industry and the Services, from which it appears that there is a strong case for pre-vocational testing and routine examination of the colour vision of school children. A concluding chapter makes a series of

- Report on Defective Colour Vision in Industry. By a Committee of the Colour Group. Pp. 52. (London: Physical Society, 1946.) 38. $6 d$. net. recommendations, of which perhaps the most important is that "all children should be tested at school at the age of 13 or over, using one of the approved Confusion Chart Tests". Confusion chart tests are also suggested as suitable for pre-vocational tests for a great variety of industries and trades.

Defective colour vision is found, we are told, in about 8 per cent of the male population, but only in a much smaller percentage of women. Of the males, only about 2 per cent are 'dichromats', a class which can match all hues with an additive mixture of two suitable primary colours, and also would be liable to make the grossest errors in colour matching; but there are many in the remaining 6 per cent who, while not liable to confuse (say) reds and greens under good lighting conditions, nevertheless have inferior powers of colour discrimination and may make substantial mistakes if the light is poor. In this group are found the 'anomalous trichromats' who, while requiring three suitable primary colours to match all hues by these primaries combined in suitable proportions, nevertheless do not usually agree with such a match made by a normal person. It is important to realize, as. is brought out by the report, that colour-defectiveness exists in many degrees of severity; there is no single condition which can be called 'colour blind'.

While the Services, public transport undertakings, and some industrial organisations prevent the entry of unsuitable persons by adequate tests, there is no consistent public policy in attempting to ensure that colour-defective persons do not become occupational misfits. The report instances the textile trades, drapery, electrical industries, paper-making, and many other cases in which a certain proportion (perhaps 20 per cent in some cases) of the employees must perform operations depending on sensitive colour discrimination. In many cases the matter is left to a kind of natural selection; people who find difficulty avoid such jobs, or they are found to be in difficulties and transferred to alternative posts. The Committee remarks in this connexion : "We have a clear impression that this loss of time and efficiency is by no means small, and that there would be real value, both from employers' and employees' points of view, in ensuring that colour-defective persons did not embark on lines of work where normal colour vision is necessary or highly desirable".

The result of a colour vision test is a matter of prime importance to the individual whose career may depend upon it. While stressing the importance of the elimination of colour-defectives from certain callings, the report proposes that the tests should occur before the individual has developed hopes which must be disappointed. We might add that any person failing should be convinced that justice has been done. While this last point is not neglected in the report, it does not seem to have been given enough weight.

The recommendation for the testing of school children is excellent, and there is no doubt that it should be implemented as soon as possible. There will be some boys who will have already been attracted to the Navy or merchant marine, and will, if colourdefective, have to turn their ambitions elsewhere. The defect is just as important in such a case as an error of refraction, and even if the test occupies five minutes of the time of a trained person, is that really an important objection? It is possible that the teachers, who already nobly carry a great burden of duties besides their normal teaching, might be able to 
include the first test as part of some instructive and amusing game in the ordinary school curriculum, and this without feeling that colour tests were the 'last straw'; there seems scope here for some invention by an educationist who is prepared to study the problem.

The report speaks in various places of the desirability of having well-printed cards for confusion chart tests, adequate lighting, proper refractive corrections, etc.: but these remarks do not appear adequately to reflect the immense importance which is rightly attached by the public to uniformity and justice in tests of this kind. In regard to one calling, the trade union concerned has taken a most active interest in such matters, and was reputed to go so far as to coach candidates in the tests. Even the school 'screening' tests should be uniform in character and adequately planned; a set of grimy cards, halfseen in a bad light, may make more trouble than they are worth. There are people who misunderstand the objects of such tests, and are capable of purchasing a set of cards for study in an attempt to defeat the examiner. If the screening test should be carefully conducted, this applies even more forcefully to the case of the testing of the doubtful cases classed in the report as Group II $a$. In spite of the convenience and undoubted effectiveness of the confusion chart method, the report leaves one with the impression that there is no guarantee that different sets of cards, even of the same supposed character, will not differ appreciably among themselves. This may not matter for a first screening test, but seems a serious drawback in the case of the decision (often difficult to make) as to whether a candidate is admissible to a particular vocation.

It may be that some means can be found of ensuring that confusion chart methods are properly controlled both in the production of the charts and their condition of use; but in this connexion my own experiences in an attempt to produce a standardized colour vision lantern may be of some interest.

In reviewing 'lantern' colour vision tests for entry to the Royal Navy, Commander Macleod found that there were considerable differences among the actual lanterns employed. A committee of the Medical Research Council, to which I had the honour of being co-opted, proposed to make the Board of Trade lantern test, known and well proved over a long period of time, the basis of a lantern test for the Royal Navy. The new lantern as re-designed, and made by Messrs. Kelvin Bottomley \& Baird, Ltd., gives almost exactly the same effects as the Board of Trade lantern, except that perhaps the luminous equality of the lights is somewhat closer. Exact equality is too elusive a fox to chase, but by the helpful co-operation of the National Physical Laboratory and the makers, we were able to formulate a set of tolerances to which all lanterns could be produced, but not without considerable effort and care. A good many lanterns have had to be corrected before they passed the careful tests of the National Physical Laboratory. This lantern is the only one, so far as I know, which is regularly produced to conform to the Laboratory's specifications. This question of guaranteed equality and testing is not mentioned in the section of the report dealing with lantern tests, though it is the essential feature of the new lantern.

I have been at some pains to emphasize this question of uniformity because I feel that the vocational tests in particular are too important to be left to somewhat haphazardmethods. The report comments, very justly, that if an electrician is tested by a matching test, using wires having clean coloured wrappings seen in a good light, he may not find the same difficulty that he does in practice when the light is poor and the wrappings dirty or faded. On the other hand, there are all degrees of dimness of light and fading, and it is possible that a person who failed in a supposedly 'realistic' test with one concern might pass in another. This may not matter much in the case of small industrial undertakings, which can please themselves about the tests they employ; but if, for example, entry to the Civil Service depends on a test, it ought to be reasonably uniform. On the bases of their possible standardization, and the satisfaction of the candidates with the tests, 'lanterns' have at present some claim to be considered for tests in cases other than those of mariners and transport workers. Every practical test is, in some degree, arbitrary.

Apart, however, from matters of secondary importance, the report should be of great public service in providing for the first time a clear general picture of the problem, and the lines along which its solution should be attempted. The rewards of success will lie in a small but definite improvement in the efficiency of industry, and (much more important) the avoidance of the disappointment and difficulty which may invade the lives of those who are unfortunate enough to suffer from defective colour vision. It is much to be hoped that the report will be carefully read by all educational authorities and persons concerned with recruitment for industry and the professions.

L. C. Martin

\section{OBITUARIES}

\section{Dame Margaret Tuke, D.B.E.}

THe largely attended memorial service in St. Paul's Cathedral on March 11 was a tribute to the memory of a woman who gave the best years of her life to the cause of women's education and who, by her inspiration and leadership, brought Bedford College to the forefront of British university colleges for women.

Dame Margaret Tuke, who died on February 21 at the age of eighty-four, was the daughter of James Hack Tuke, of Hitchin, Herts. She was educated at St. John's, Withdean, Brighton, from which school she proceeded to Newnham College, Cambridge, where she read for the Medieval and Modern Languages Tripos. She was appointed to a lectureship in modern languages at Newnham in 1890 and continued in Cambridge until 1905, in which year she accepted the tutorship to women students and a lectureship in French at University College, Bristol. After two years at Bristol, she was appointed principal of Bedford College for Women, then occupying inadequate buildings in Baker Street, London. During Miss Tuke's tenure of the principalship, the College grew in size and importance, and its academic standing became firmly established. It was moved to its present site in Regent's Park and, largely owing to her initiative and energy, extended its range of studies considerably, especially in the natural sciences. Laboratories for botany, chemistry, geology, physics, physiology and zoology were opened, designed to provide adequate facilities for advanced teaching and research work. Additions were also made to the number of subjects in the Faculty of 